\title{
Optimal Fish Harvesting with Deterioration, Effort and Price- Sensitive Demand
}

\author{
Nita H. Shah ${ }^{*}$, Bijal M. Yeolekar ${ }^{2}$ \\ ${ }^{1,2}$ Department of Mathematics, Gujarat University, Ahmedabad, 380009, Gujarat, India \\ Email: nitahshah@gmail.com, bijalyeolekar28@gmail.com
}

\begin{abstract}
The dynamics of a fishery resource system is formulated for fish harvesting with effort and price-sensitive demand. The model considers deterioration as damage during catchability. It is assumed that the supply is instantaneous. The system of non-linear differential equations is formulated and solved to determine the non-trivial equilibrium. The conditions for stability of equilibria are worked out. The numerical data are used to support theoretical results derived.
\end{abstract}

Keywords: Fishery harvesting, effort, price-sensitive demand, deterioration, stability

\section{Introduction}

For maximum sustainability of renewable resources, the proper study of its dynamics is required. The over-exploitation of the resource decreases productivity. Clark [5] focused on the existence of Maximum Sustainable Yield (MSY) for studying the dynamics of renewable resources. Biologically, when several ecologically independent species are harvested, Maximum Sustainable Yield is not easy to achieve. Also, MSY does consider the benefits of resource exploitation but ignores the cost of resource exploitation. Kar and Chakraborty [9] argued that if a species is harvested to an extent that its population reduces to a certain level, then the cost of harvesting will be expensive. This will lead to a scenario when benefit is very seldom compared to the cost of effort. Murray [17], Smith [23][24], Barbier et.al. [3] discussed harvesting models with constant price of resource or a function of variables and catchability. Auger et al. [2] discussed fishery model of resource exploitation with variable price as an extension of Mchich et al. [14] 2006), Kar and Chaudhuri [10] formulated a bio-economic model of two-prey and one-predictor. Kronbak [13] discussed a dynamics open-access model of a single industry exploiting a single stock. Mikkelsen [16] used Verhulst-Schaefer model of fish-population-dynamics and production to investigate the effect of habitat, wild fish stock genetics, or fishing efficiency under open-access and rent maximizing fisheries. Other related articles are by Kar and Matsuda [11], Kar and Chakrabourty (2003), Wang et al. [26], Patra et al. [19], Pitcher et al. [20], Pomeroy et al. [21], Prellezo et al. [22], Mansal et al. [15] and Thorpe et al. [25].

The above cited references have missed the fact that during catching/stocking/mis-handling fishes lose it's utility. In the present study, a bio-economical model considers deterioration in Mansal et al. [15]. Here, deterioration is regarded as the loss of utility of the fishes for the aimed purpose which may be medicinal or food. This results in the loss of effort and profit.

The paper is organised as follows: the mathematical model of fishery with deterioration and a variable price is formulated in section 2 with analytical results. The results are numerically validated in section 3. A conclusion section summarises the study.

\section{$2 \quad$ Mathematical Model}

The system deals with single harvesting costal area. Let $N(t)$ denote fish stock, $E(t)$ denote the fishing effort, $P(t)$ denote the variable price at time $t$ and $\theta,(0 \leq \theta \leq 1)$ denote the constant rate of deterioration. The following system of differential equations governs the dynamics of the model: 


$$
\begin{aligned}
\frac{d N(t)}{d t} & =r N(t)\left(1-\frac{N(t)}{k}\right)-q N(t) E(t)-\theta q N(t) E(t) \\
\frac{d E(t)}{d t} & =q N(t) E(t) P(t)(1-\theta)-c E(t) \\
\frac{d P(t)}{d t} & =a-b P(t)-q N(t) E(t)
\end{aligned}
$$

In the first differential equation, $r>0$ is the fish growth rate and $k>0$ is the catching capacity of the harvesting region. The quantity of fish harvested per unit time, $q N(t) E(t)$ defines $q$ proportion of the fishing effort $E(t)$ and the fish stock $N(t)$. The third term defines $\theta \%$ deterioration of the quantity harvested.

The second differential equation defines the rate of change of effort which is the difference between the revenue generated by selling harvested quantity at price $p$ per unit per unit time and effort required at maintenance cost $c>0$ per fishing effort unit per unit time with loss due to deterioration.

The third equation denotes the rate of change of selling price which increases when demand is more than the offer. The demand is assumed to be a linearly decreasing function of selling price, with $a$ as maximum scale demand, $b>0$ as price elasticity mark up.

\subsection{Existence of Equilibria}

The system (1) has the following nullclines:

- The $N$-nullclines gives $N=0$ and $E=\frac{r}{q(1+\theta)}\left(1-\frac{N}{k}\right)$.

- The $E$-nullclines gives $E=0$ and $N=\frac{c}{p q(1-\theta)}$.

- The $P$-nullclines gives $p=\frac{a-q N E}{b}$.

With these nullclines, we have equilibrium $X_{0}=\left(0,0, \frac{a}{b}\right)$ denoting the extinction of fish population $X_{k}=\left(k, 0, \frac{a}{b}\right)$ which is obtained when there is no fishing, and a positive equilibrium $X^{*}=\left(N^{*}, E^{*}, p^{*}\right)$ with $N^{*}=\frac{c}{p^{*} q(1-\theta)}, E^{*}=\frac{r}{q(1+\theta)}\left(1-\frac{N^{*}}{k}\right), p^{*}=\frac{a-q N^{*} E^{*}}{b}$.

The assumption that demand is equal to offer results into non-trivial equilibrium and is given by

$$
a-b p^{*}=\frac{r c}{p^{*} q\left(1-\theta^{2}\right)}\left(1-\frac{c}{p^{*} q k(1-\theta)}\right)
$$

Equation (2) is known as the Market Price Equation (or MPE), is cubic in $p$ which is given by

$$
p^{3}\left(b q^{2} k(1+\theta)(1-\theta)^{2}\right)-p^{2}\left(q^{2} k a(1+\theta)(1-\theta)^{2}\right)+p(r c q k(1-\theta))+\left(-r c^{2}\right)=0
$$

Hence, using Cardon's formula, in (3) the discriminant $\Delta_{b}$ of polynomial and its derivated polynomial is $\Delta_{b}=F\left(p_{b}, p_{b}{ }^{\prime}\right)=q^{6} b r c^{2} k^{3}(1-\theta)^{6}(1+\theta) \cdot G(b)$

where $G(b)=27 b^{2} r c^{2}(1+\theta)-18 b q k r c a\left(1-\theta^{2}\right)+4 a^{3} q^{2} k\left(1-\theta^{2}\right)^{2}-a^{2} q^{2} k^{2} r(1-\theta)^{3}+4 b q k^{2} r^{2} c(1-\theta)$ is a quadratic polynomial with roots $b^{+}=\frac{q(\theta-1)}{27 c r(1+\theta)}\left[2 r^{2} k^{2}+q k a r(1+\theta)+2 \sqrt{27 k r\left(\frac{k r}{3}-a(1+\theta)\right)^{3}}\right]$ and $b^{-}=\frac{q(\theta-1)}{27 c r(1+\theta)}\left[-2 r^{2} k^{2}+q k a r(1+\theta)-2 \sqrt{27 k r\left(\frac{k r}{3}-a(1+\theta)\right)^{3}}\right]$. 
The system (1) has three positive equilibria depending on values of model parameters as:

- If $b>\frac{q k a(1+\theta)}{c}$, there is no positive equilibrium.

- If $b<\frac{q k a(1+\theta)}{c}, k r<3 a(1+\theta)$, there is exactly one positive equilibrium.

- If $b<\frac{q k a(1+\theta)}{c}, k r>3 a(1+\theta)$, there are three cases:

1. If $b<b^{-}$, there is one and only one positive equilibrium;

2. If $b^{-}<b<b^{+}$, there are three positive equilibria;

3. If $b^{+}<b$, there is one and only one positive equilibrium.

\section{$2.2 \quad$ Stability Criteria}

The Jacobian matrix of system (1) at equilibrium points and stability status are exhibited in Table 1.

Table 1. Stability status of system

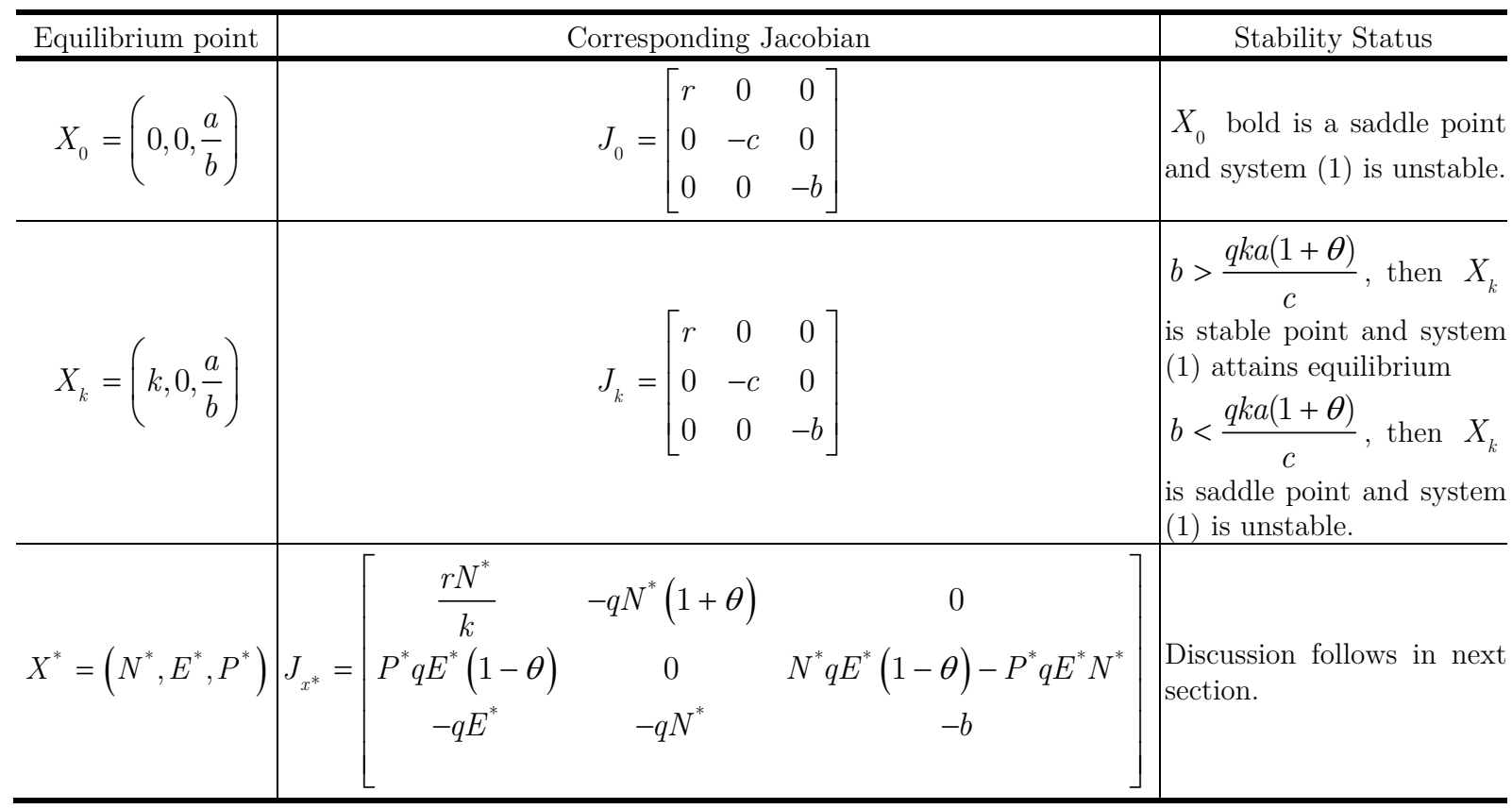

For stability of positive equilibria of system (1), the following two cases hold.

If $a(1-\theta)>\frac{k r}{3}$, there exists a unique positive equilibrium $X^{*}$ which is locally asymptotically stable.

If $a(1-\theta)<\frac{k r}{3}$, a positive equilibrium is locally asymptotically stable if and only if

$P^{*}<P^{-}$or $P^{*}>P^{+}$, where $P^{+}=\frac{\left[k r+\sqrt{k r(k r-3 a(1+\theta))^{3}}\right]}{q k a(1+\theta)} c$ and $P^{-}=\frac{\left[k r-\sqrt{k r(k r-3 a(1+\theta))^{3}}\right]}{q k a(1+\theta)} c$

hold for system (1).

Next, we check the model numerically for each case and for stability.

\section{$3 \quad$ Numerical Study and Interpretation}

Consider, the initial conditions as $N(0)=1, E(0)=P(0)=2$, the deteriorate rate $\theta=50 \%$. This is legitimate as life span of fish is small enough. We illustrate working of the results for different cases as 
follows.

Example 1. Take $b=40 \%, q=10 \%, \quad k=8$ units, $\quad r=0.9$ units $a=2$ units, $c=2$, then $\frac{q k a(1+\theta)}{c}=$ $0.88<0.4=b$. The dynamics of fish stock, efforts, and demand is shown in Figure 1 .

It is observed that fish stock attains equilibrium after 8 hours. Fishing efforts decreases sharply and stabilizes after 2.8 hours. The fish-stock and effort are required only for 0.4 hours, during this time player catches sufficient fishes.

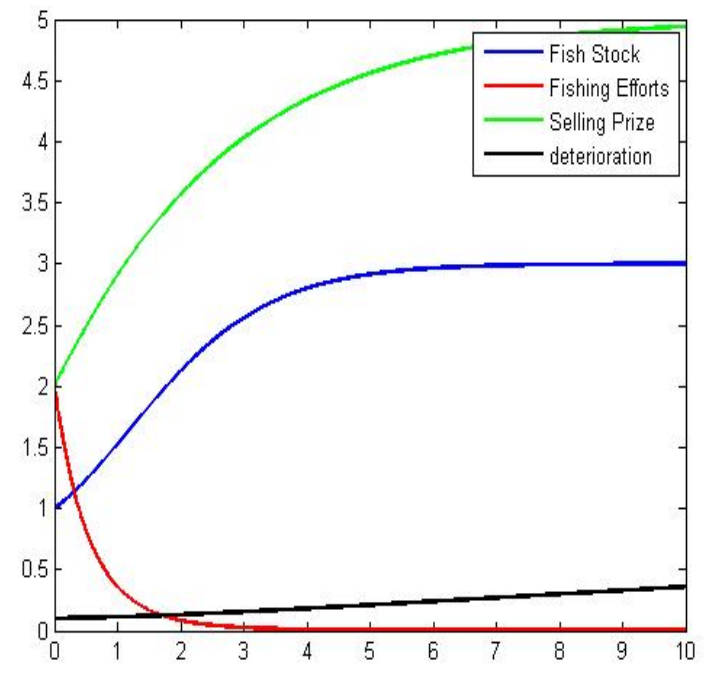

Figure 1. Stable equilibrium at $X_{k}=\left(k, 0, \frac{a}{b}\right)$ with $b>\frac{q k a(1+\theta)}{c}$

In Figure 2, we observe that fish stock increases up to 7 hours and then becomes constant. For maintaining this fish stock, effort is required up to 3 hours. During first 5.5 hours selling price and deterioration are increasing. With this data, up to 4-degree, polynomial fits are obtained as

$$
\begin{aligned}
& N(t): 0.0002 x^{4}+0.0008 x^{3}-0.0851 x^{2}+0.7930 x+0.8726 \\
& E(t): 0.0021 x^{4}-0.0498 x^{3}+0.4048 x^{2}-0.3533 x+1.5004 \\
& P(t): 0.0003 x^{4}+0.0118 x^{3}-0.1604 x^{2}+1.0697 x+1.9889
\end{aligned}
$$
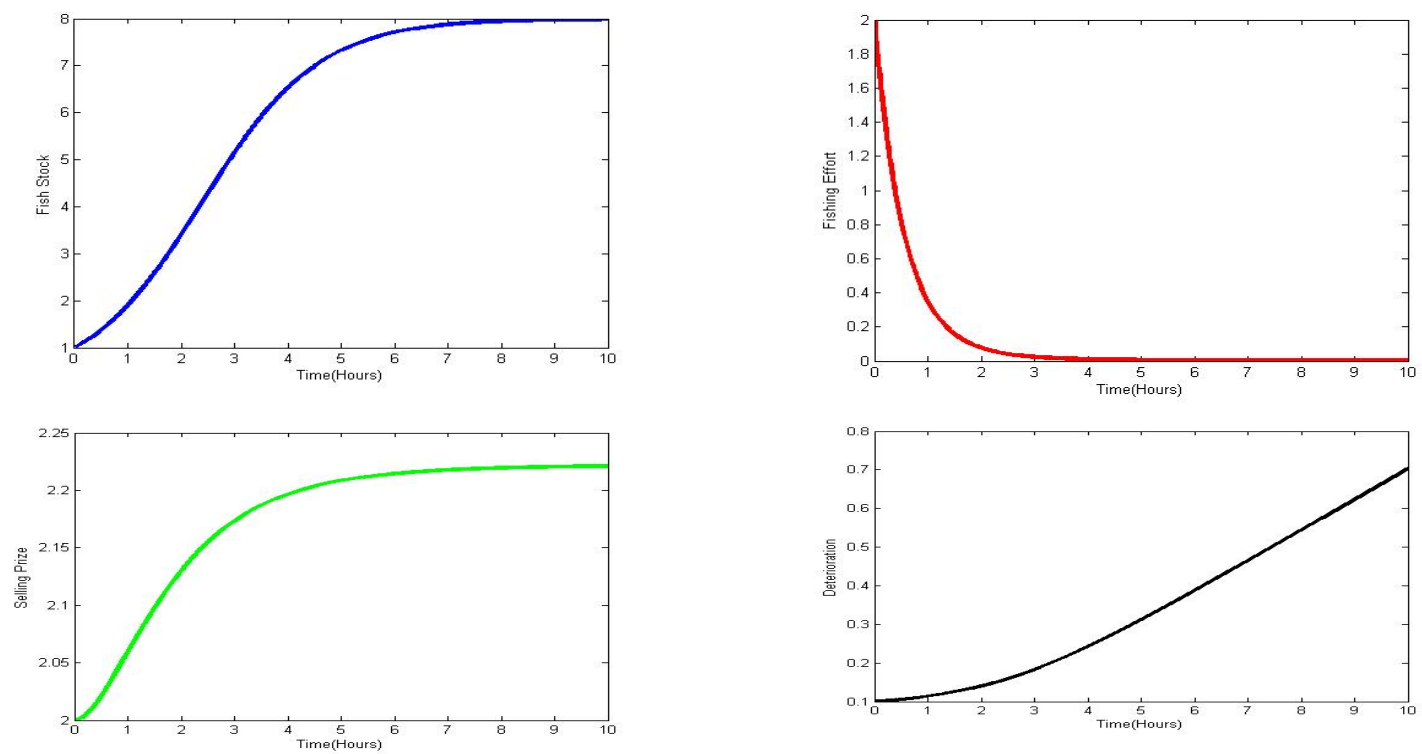

Figure 2. Dynamics of fish stock, effort, selling price and deterioration 
Example 2. Using the same data as given in Example 1 with $b=10 \%$, and $k=3$ units, $\frac{q k a(1+\theta)}{c}=$ $0.33>0.1=b$ and also $3 a(1+\theta)=6.6>2.7=k r$, then analytically it is established that the system is unstable. It is shown in Figure 3.

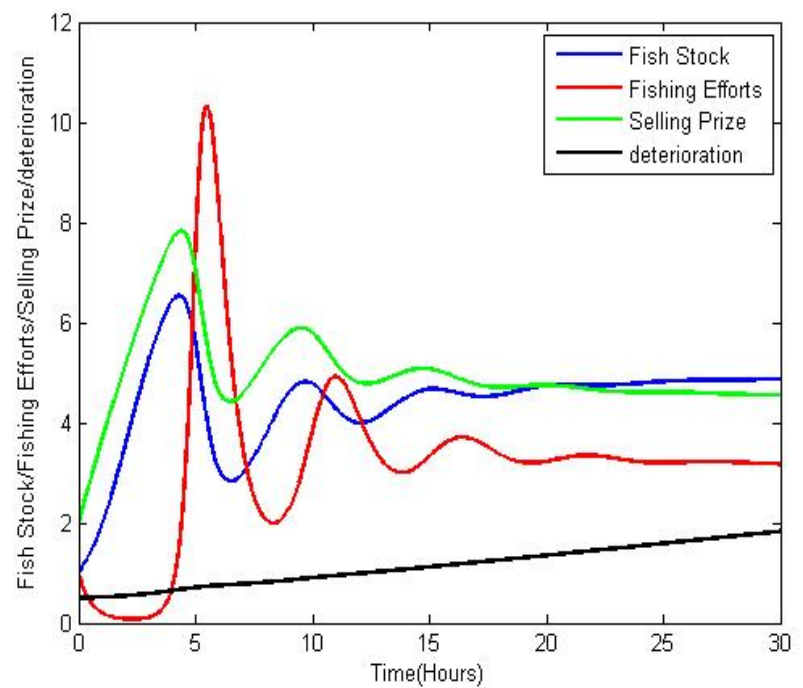

Figure 3. An unstable system at $X_{k}=\left(k, 0, \frac{a}{b}\right)$ with $b<\frac{q k a(1+\theta)}{c}$ and $k r<3 a(1+\theta)$

Example 3. Using the same data as in Example 2 and taking $k=8$ units, we have $3 a(1+\theta)=$ $6.6<7.2=k r$. As proved in analytical results, the system is unstable as shown in Figure.4.

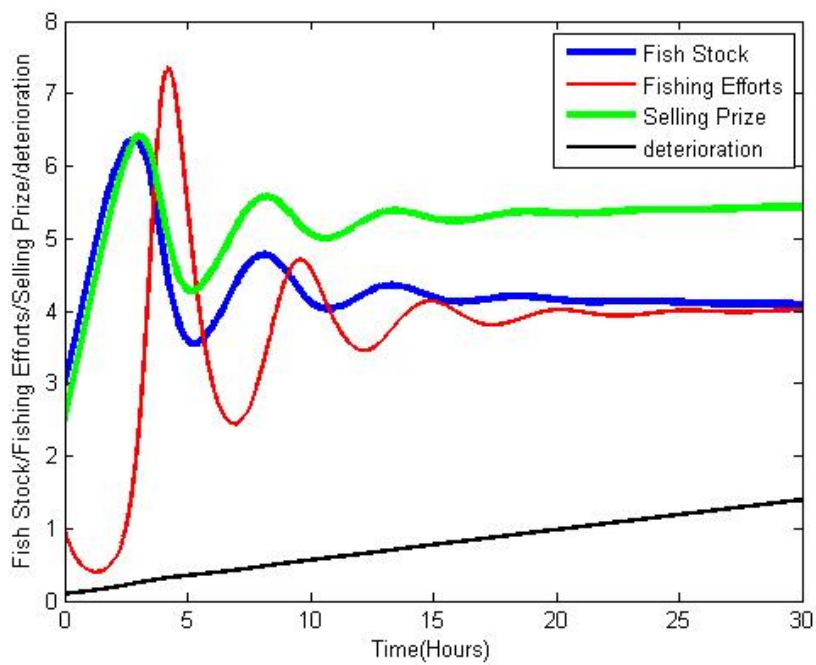

Figure 4. Unstabillity of system at $X_{k}=\left(k, 0, \frac{a}{b}\right)$ with $b<\frac{q k a(1+\theta)}{c}$ and $k r>3 a(1+\theta)$.

It is observe from the Figure.4, that selling price and fish stock intersect only at one point. Fishing effort and stock and selling price behave oppositely. For the first two hours, fishing effort decreases and thereafter it oscillates.

Next, we analyse stability of the system at $X^{*}=\left(N^{*}, E^{*}, P^{*}\right)$.

Example 4. Take $b=80 \%, q=10 \%, k=3$ units, $r=0.9$ units, $a=2$ units, $c=2$, with $50 \%$ deterioration, then $\frac{q k a(1+\theta)}{c}<b$. For this scenario, the system has no equilibrium, as shown in Figure 5. 


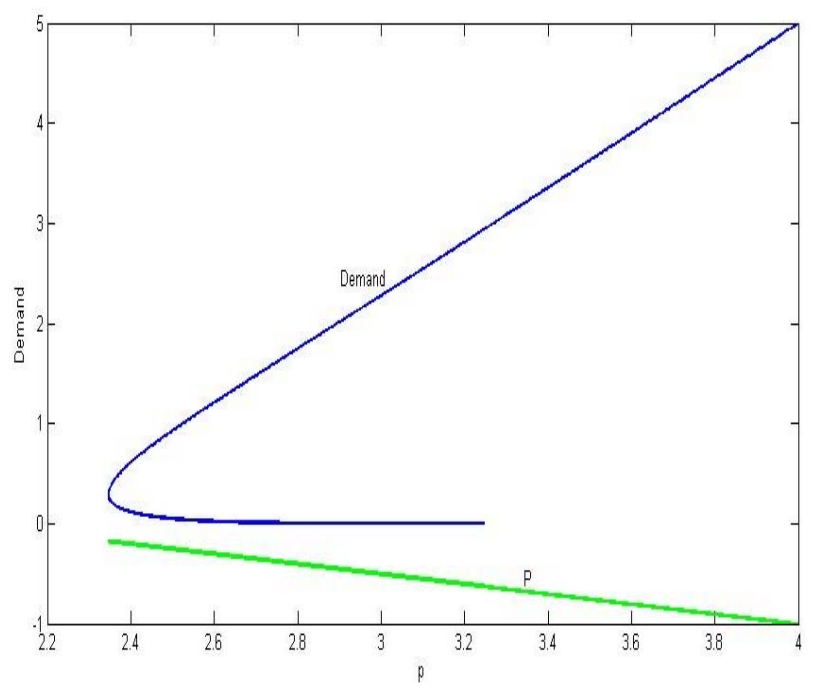

Figure 5. System has no equilibrium point

This indicates that demand and price never satisfies either a customer or a fishery man. Then fisherman will not put any effort in harvesting and consequently, the firm will shut down the shutters.

Example 5. With the same data in Example 4 with $k=6$ units, then $\frac{q k a(1+\theta)}{c}>b$ and also $k r<3 a(1+\theta)$. As shown in Figure 6 , the system has one equilibrium point at $p=\$ 2.25$. The economical interpretation is, demand is satisfied with expected generation of revenue.

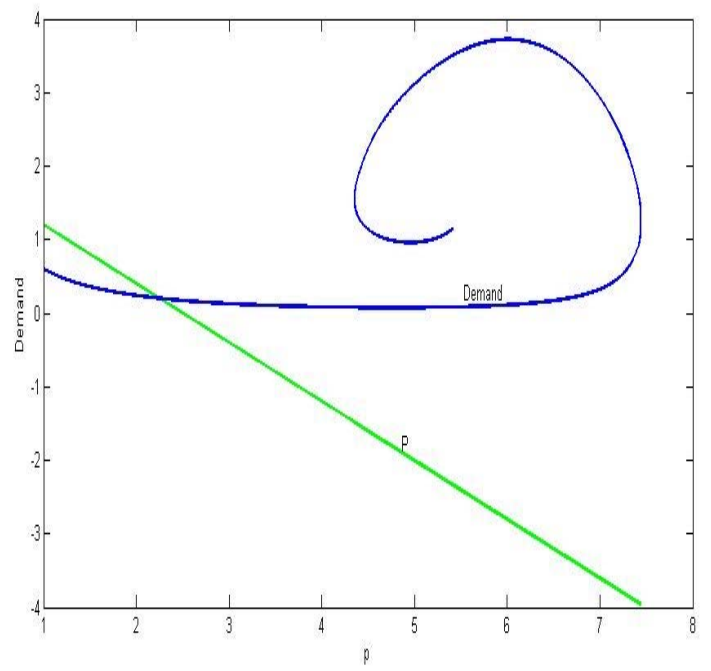

Figure 6. System has exactly one equilibrium point

Example 6. Using the same data as in example 5 except $k=1$, and $b=3 \%$ then $\frac{q k a(1+\theta)}{c}>b$ and also $k r>3 a(1+\theta)$. As shown in Figure 7, the system attains three equilibria, one when $p=0$ (because it cannot be negative) and the others at $p=\$ 4.5$ and $p=\$ 7$. This result suggests that fishery firm should be shut down if target revenue is not obtained. 


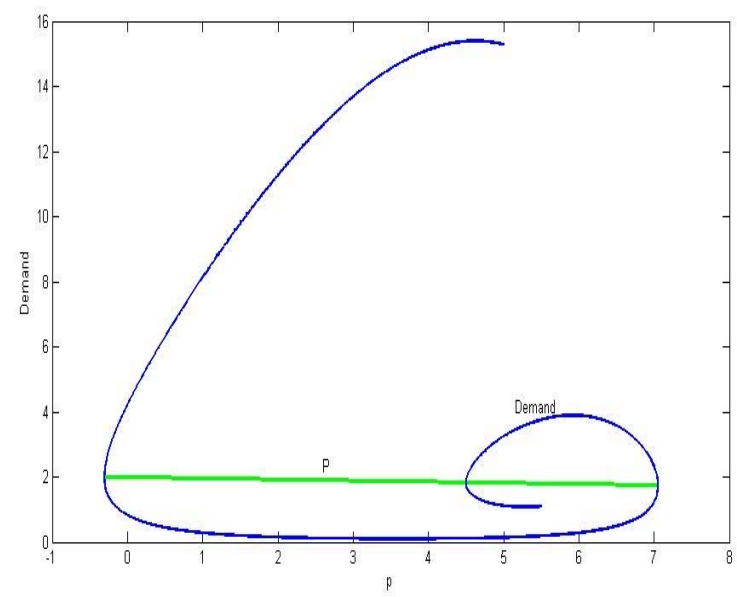

Figure 7. System with three equilibrium points

\section{Conclusion}

In the present study, we formulated fishery harvesting model where some part of catchability loses its utility. The demand is considered to be a decreasing function of selling price. The scenarios are worked out to make a decision for optimal effort to maximize the profit. The conditions are established in which harvesting is beneficial to players viz. fisherman and end-user.

Acknowledgements: The authors thank anonymous reviewers and editor for constructive comments. The authors thank DST-FIST-2014 File \# MSI-097 for providing technical support to the Department of Mathematics, Gujarat University, Ahmedabad, India.

\section{References}

1. P. Auger and A. Ducrot, "A model of a fishery with fish stock involving delay equation", Philosophical Transactions of the Royal Society A, vol. 367, no. 1098, pp 4907-4922, 2009.

2. P. Auger, R. Mchich, N. Raissi and B.W. Kooi, "Effects of market 1`price on the dynamics of a spatial fishery model: over-exploited fishery/traditional fishery", Ecological Complexity, vol. 7, no 2010, pp. 13-20, 2009.

3. E.B. Barbier, I. Strand and S. Sathirathai, "Estimating the welfare effects of mangrove-fishery linkages in Thailand", Environmental and Resource Economics, vol. 21, no. 4, pp. 343-367, 2002.

4. C.W. Clark, Bio economical modelling and fishery management. John Willey and Sons, 1985.

5. C.W. Clark, Mathematical bio-economics: The optimal management of renewable resources. John Wiley and Sons, $2^{\text {nd }}$ edition, 1990 .

6. C.W. Clark, "Fishery bio-economics: why is it so widely misunderstood?", Population Ecology, Springer, vol. 48, no. 2, pp. 95-98, 2006.

7. M. De Lara, and L. Doyen, Sustainable management of renewable resources: mathematical models and methods. Springer Science \& Business Media, 2008.

8. L. Doyen, A. Cisse, S. Gourguet, L. Mouysset, P. Y. Hardy, C. Bene, F. Blanchard, F. Jiguet, J. C. Pereau and O. Thebaud, "Ecological-economic modelling for Sustainable management of biodiversity". Computational Management Science, vol. 10, no. 4, pp. 353-364, 2013.

9. T. K. Kar and K. Chakraborty, "Bio-economic analysis of Maryland's Chesapeake Bay oyster fishery with reference to the optimal utilization and management of the resource", International Journal of Engineering, Science and Technology, vol. 1, no. 1, pp. 172-189, 2009.

10. T. K. Kar and K. S. Chaudhuri, "Harvesting in a two-prey one-predator fishery: A bio- economic model", The ANZIAM Journal, vol. 45, no. 3, pp. 443-456, 2004. 
11. T. K. Kar and H. Matsuda, "A bio-economic model of a single-species fishery with a marine reserve", Journal of environmental management, vol. 86, no. 1, p. 171-180, 2008.

12. T. K. Kar, S. Misra and B. Mukhopadhyay, "A bio-economic model of a ratio-dependent predator-prey system and optimal harvesting", Journal of Applied Mathematics and Computing, vol. 22, no. 1-2, pp. 387-401, 2006.

13. L. G. Kronbak, "The dynamics of an open-access fishery: Baltic Sea cod. Marine Resource Economics, vol. 19, no. 4, pp. 459-479, 2004.

14. R. Mchich, P. M. Auger, R. B. De La Parra and N. Raissi, "Dynamics of a fishery on two fishing zones with fish stock dependent migrations: aggregation and control", Ecological modelling, vol. 158, no. 1, pp. 51-62, 2002.

15. F. Mansal, T. Nguyen-Huu, P. Auger, and M. Balde, "A mathematical model of a fishery with variable market price: sustainable fishery/over-exploitation", Actabiotheoretica, vol. 62, no. 3, pp. 305-323, 2014.

16. E. Mikkelsen, "Aquaculture-fisheries interactions", Marine Resource Economics, vol. 22, no. 3, pp. 287-303, 2007.

17. J. D. Murray, Mathematical Biology. Springer, 1993.

18. E. Meuriot, Les modeless bio-economics d'exploitation des pecheries. Demarches etenseignements. Rapports economiquesetjuridiques de 1' IFREMER N 4, 1987.

19. B. Patra, A. Maiti and G. P. Samanta, "Effect of time-delay on a ratio-dependent food chain model", Nonlinear Analysis: Modelling and Control, vol. 14, no. 2, pp. 199-216, 2009.

20. T. J. Pitcher, D. Kalikoski, K. Short, D. Varkey, G. Pramod, "An evaluation of progress in implementing ecosystem-based management of fisheries in 33 countries", Marine Policy, vol. 33, no. 2, pp.223-232, 2009.

21. R. Pomeroy, K. A. T. Nguyen and H. X. Thong, H. X., "Small-scale marine fisheries policy in Vietnam", Marine Policy, vol. 33, no. 2, pp. 419-428, 2009.

22. R. Prellezo, P. Accadia, B. S. Andersen, E., Buisman, A. Little, J. R. Nielsen, J.J. Poos, J. Powell and C. Rockmann, "A review of EU bio-economic models for fisheries: the value of a diversity of models", Marine Policy, vol. 36, no. 2, pp. 423-431, 2012.

23. V. L. Smith, "Economics of production from natural resources", American Economic Review, vol. 58, no. 3, pp. 409-431, 1968.

24. V. L. Smith, "On models of commercial fishing", Journal of Political Economy, vol. 77, no. 2, pp. 181-198, 1969.

25. A. Thorpe, D. Whitmarsh, E. Ndomahina, A. Baio, M. Kemokai and T. Lebbie, "Fisheries and failing states: The case of Sierra Leone". Marine Policy, vol. 33, no. 2, pp. 393-400, 2009.

26. L. Wang, R., Xu and X. Tian, "Global stability of a predator-prey model with stage structure for the Predator", World Journal of Modelling and Simulation, vol. 5, no. 3, pp. 192-202. 